\title{
Control Method of Photovoltaic Maximum Power Point Tracking Based on the Theory of fuzzy
}

\author{
Xuecheng Zhao ${ }^{1, a}$, Yuhong Zhao ${ }^{2, b}$ \\ ${ }^{1}$ Mechanical and Electrical Engineering Department ,Shaoyang Vocatioonal \& Technical, Shaoyang, \\ Hunan, China \\ ${ }^{2}$ Institute of Electrical Engineering, University of south China, Hengyang, Hunan, China \\ aljzy666@163.com, b gsx1666@163.com
}

Keywords: photovoltaic power system; maximum power point tracking; fuzzy control

\begin{abstract}
Output power of Photovoltaic cells with nonlinear characteristics is affected by temperature, light intensity and load. In order to improve photoelectric conversion efficiency, maximum power point tracking (MPPT) is required. According to the mechanism and control methods of Maximum Power Point Tracking (MPPT), a new modified adaptive duty cycle perturbation MPPT method which is based on fuzzy control is presented. The experimental results show the proposed system can track the MPP quickly, exactly and steadily.
\end{abstract}

\section{Introduction}

Photovoltaic power generation system can directly convert solar energy into electrical energy. The current - voltage output of photovoltaic battery is nonlinear, coupled with changes in the sunshine, temperature and other factors, the output power is constantly changing. In order to improve the utilization of the whole system, which is in theory and practice on the maximum power point tracking of PV systems (Maximum Power Point Tracking, MPPT) [1]. The feedback control of maximum power point tracking is usually based on power as a variable, which play the role of the photovoltaic cell internal resistance and external load impedance matching. The fuzzy control is a typical intelligent control method, its most important feature is the experience and knowledge of the experts used to control the language rules, it does not rely on the precise mathematical model of controlled object and be able to overcome the nonlinear effects. In the photovoltaic power generation system, we usually via a DC / DC or DC / AC connected photovoltaic arrays and load, adjust the PWM duty cycle to achieve optimal matching of the damping, so that maximum output power can be achieved. Fuzzy control can automatically adjust the duty cycle based on the magnitude of the power change, quick to perceive the external environment changes, in the case that does not interfere with the normal work of the system, find the maximum power point. Thus, the adaptive duty cycle disturbances MPPT method based on fuzzy logic control is proposed. [2]

\section{Photovoltaic Cell Characteristics}

Photovoltaic Cell Mathematical Model and the Output Characteristics. According to the electronic theory, the equivalent mathematical model of the photovoltaic cells is:

$$
\begin{aligned}
& I=I_{s c}-I_{o}\left[\exp \left[\frac{q\left(V+I R_{s}\right)}{A K T}\right]-1\right]-\frac{V+I R_{s}}{R_{s h}} \\
& \text { in which } I_{s c}=\left[I_{s c r}+K_{I}(T-298)\right] \frac{S}{100} \\
& I_{o}=I_{o r}\left(\frac{T}{T_{r}}\right)^{3} \exp \left[\frac{q E_{c o}}{A K}\left(\frac{1}{T_{r}}-\frac{1}{T}\right)\right]
\end{aligned}
$$

Where I and V is respectively the battery output current and port voltage; $\mathrm{I}_{\mathrm{sc}}$ is the photocurrent; $\mathrm{I}_{0}$ is the battery internal equivalent diode PN junction reverse saturation current; $q$ is the charge of an 
electron; A is diode PN junction ideality factor; $\mathrm{K}$ is the Boltzmann constant, $1.38 \times 10-23 \mathrm{~J} / \mathrm{K}$; $\mathrm{T}$ is the operating temperature of photovoltaic cells; $\mathrm{R}_{\mathrm{s}}$ is the battery's series resistance; $\mathrm{Tr}$ is the absolute temperature, $273 \mathrm{~K} ; \mathrm{I}_{\text {or }}$ is the diode saturation drain current under $\mathrm{T}_{\mathrm{r}} ; \mathrm{E}_{\mathrm{co}}$ is the width of silicon; $\mathrm{S}$ is the light intensity, $\mathrm{W} / \mathrm{m}^{2}$; $\mathrm{I}_{\mathrm{scr}}$ is the short-circuit current under the conditions of $298 \mathrm{~K}$ and of $1000 \mathrm{~W}$ $/ \mathrm{m}^{2} ; \mathrm{K}_{\mathrm{I}}$ is short-circuit current temperature coefficient under the conditions of $\mathrm{I}_{\mathrm{scr}}$.

Affected by environmental factors such as light, temperature, the output characteristics of photovoltaic cells has the obvious nonlinear. Based on the above model can make the IV and PV curves of photovoltaic cells under different light and temperature conditions as shown in Figure 1.

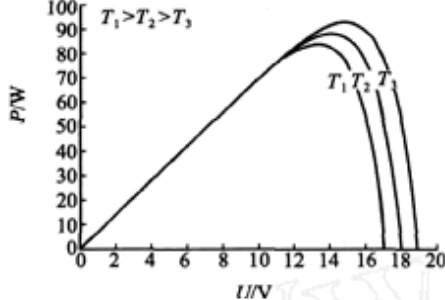

(a)

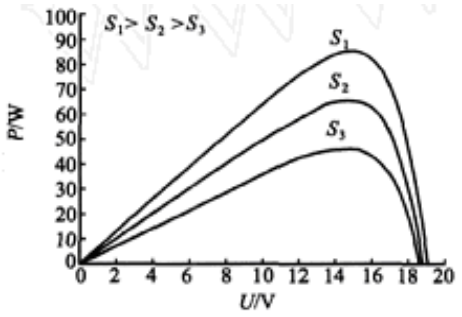

(c)

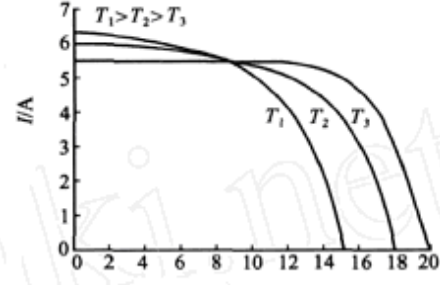

(b)

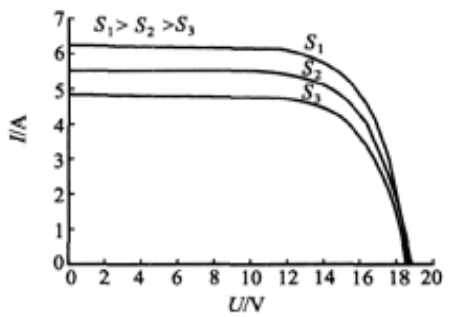

(d)

(a) The PV curve of the battery under different temperature conditions of the same light

(b) The IV curve of the battery under different temperature conditions of the same light

(c) The PV curve of the battery under different light conditions of the same temperature

(d) The IV curve of the battery under different light conditions of the same temperature

Fig. 1 The output characteristics of photovoltaic cells

\section{The Basic Principles of Fuzzy Control}

The Input and Output of Fuzzy Controller. We take the PV system's output power as the objective function and duty cycle as control variables. According to the variation of the power value and the duty cycle adjustment step before the moment, we can determine step size that need to adjusted at this moment. The first $n$ moments of the fuzzy controller input is the $n$-moment variation of the power photovoltaic system and the n-1 time of the duty cycle step, the n-th time output is the first $\mathrm{n}$ moments of the duty cycle step. [3]

Determine the Input and Output Fuzzy Subset and Domain. In order to facilitate control, the quantitative factor to quantify the actual value of the power variable ep (n) and duty cycle step ed (n), respectively are mapped to fuzzy set theory domain Ep and, Ed. Fuzzy set theory domain Ep and Ed are defined as a fuzzy subset of eight and six, that is,

$\mathrm{Ep}=\{\mathrm{NB}, \mathrm{NM}, \mathrm{NS}, \mathrm{NO}, \mathrm{PO}, \mathrm{PS}, \mathrm{PM}, \mathrm{PB}\}$

$\mathrm{Ed}=\{\mathrm{NB}, \mathrm{NM}, \mathrm{NS}, \mathrm{PS}, \mathrm{PM}, \mathrm{PB}\}$

Among them: NB, NM, NS, NO, PO, PS, PM, PB respectively denote negative big, negative medium, negative small, negative zero, positive zero, positive small, middle, positive big vague concept. The fuzzy set theory domain Ep and Ed adopt the discrete set of numbers, as follows:

$\mathrm{Ep}=\{-6,-5,-4,-3,-2,-1,-0,+0,+1,+2,+3,+4,+5,+6\}$

$\mathrm{Ed}=\{-6,-5,-4,-3,-2,-1,+1,+2,+3,+4,+5,+6\}$

Membership Grade Function. According to the characteristics of PV systems, we select the triangle as the shape of membership function .The closer the curve from the origin (the smaller the error), the curve is steeper (the higher the resolution); the farther from the origin (the greater the error), the curve is more slow(the lower the resolution). Power difference between Ep and the membership function of the duty cycle step Ed, as shown in Figure 2, Figure 3 shows. 


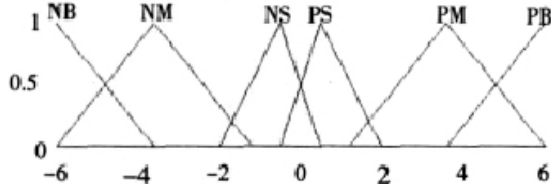

Fig.2 Power error membership functions

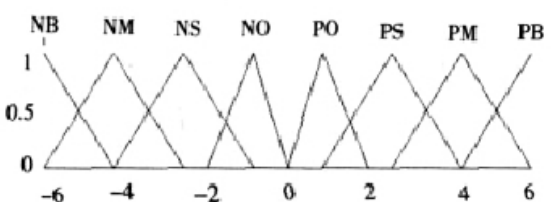

Fig.3 Duty cycle membership functions

Fuzzy Decision Table. According to the analysis of the characteristic curve between the PV system output power $\mathrm{P}$ and the duty cycle $\mathrm{D}$ can be obtained the following principles.

(1) If the output power increases, continue to adjust to the long direction of the original step, otherwise take the opposite direction.

(2)maximum power point farther away, larger step to accelerate the tracking speed; near the maximum power point, using a smaller step size to reduce the search losses.

(3)temperature, sunlight intensity, and factors such as changes lead to larger changes in the power of the photovoltaic system, the system can quickly respond.

According to the above principles, we apply IF A AND B THEN C fuzzy rules to get the fuzzy rules (Table 1).

Tab.1 Control rule table of fuzzy control

\begin{tabular}{|c|c|c|c|c|c|c|c|c|}
\hline \multirow{2}{*}{$A$} & \multicolumn{8}{|c|}{$E$} \\
\hline & $N B$ & $N M$ & $N S$ & $\mathrm{NO}$ & $P O$ & $P S$ & $P M$ & $P B$ \\
\hline$N B$ & $P B$ & $P M$ & $P S$ & $P S$ & $N S$ & $N S$ & $N S$ & $N S$ \\
\hline$N M$ & $P B$ & $P B$ & $P M$ & $P S$ & $N S$ & $N S$ & $N S$ & $N S$ \\
\hline$N S$ & $P B$ & $P B$ & $P M$ & $P S$ & $N S$ & $N S$ & $P B$ & $N S$ \\
\hline$P S$ & $N S$ & $N S$ & $N S$ & $N S$ & $P S$ & $P M$ & $P B$ & $P B$ \\
\hline$P M$ & $N S$ & $N S$ & $N S$ & $N M$ & $P M$ & $P M$ & $P B$ & $P B$ \\
\hline$P B$ & $N S$ & $N S$ & $N S$ & $N M$ & $P M$ & $P S$ & $P M$ & $P B$ \\
\hline
\end{tabular}

Simulation Experiment. According to the mathematical model of the PV array, solar cell model is established by Matlab/Simulink. The duty cycle step function is used to achieve $D(n)=D(n-1)+d$ (n) of functions. Solar model parameters is set as follows: Temperature coefficient of voltage: $0.8 \mathrm{~V} /{ }^{\circ} \mathrm{C}$; current temperature coefficient: $0.016 \mathrm{~V} /{ }^{\circ} \mathrm{C}$; series resistance: $2 \Omega$; open circuit voltage of $320 \mathrm{~V}$; short-circuit current of $10.8 \mathrm{~A}$; reference temperature: $26^{\circ} \mathrm{C}$; reference solar radiation: $1000 \mathrm{~W} /{ }^{\circ} \mathrm{C}$; maximum power voltage: $300 \mathrm{~V}$; maximum power current: 10.3A. [4] [5]

Simulation conditions are: the surface temperature of photovoltaic cells for $26^{\circ} \mathrm{C}$; simulation time for $2 \mathrm{~S}$; the initial value of duty cycle for 1 ; the sunlight intensity simulated in the first seconds from $800 \mathrm{~W} / \mathrm{m}^{2}$ increased sharply to $1000 \mathrm{~W} / \mathrm{m}^{2}$. Do not use control and adopt fuzzy control simulation, the power output respectively shown in Figure 4, Figure 5.

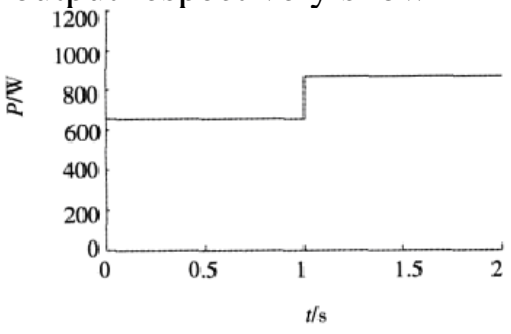

Fig.4 Output duty cycle (fuzzy control)

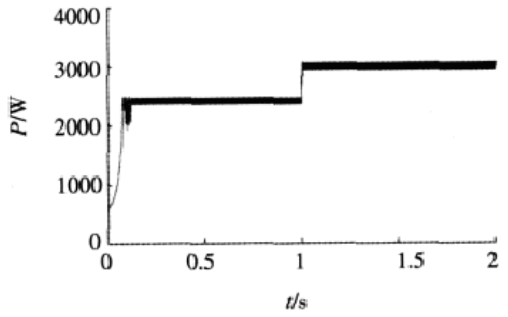

Fig.5 Output power (fuzzy control)

Can be seen from Figure 4, when the PV system is running at the sunlight intensity for $800 \mathrm{~W} / \mathrm{m}^{2}$ the output power is $656 \mathrm{~W}$; When the system runs to $2 \mathrm{~s}$, sunshine intensity step to $1000 \mathrm{~W} / \mathrm{m}^{2}$, the output power is $866 \mathrm{~W}$. Can be seen from Figure 5, the use of fuzzy control system, after $0.12 \mathrm{~s}$, the power output become stable, and oscillations near the $2421 \mathrm{~W}$; when the light intensity mutations, the system becomes stable after $0.006 \mathrm{~s}$, and oscillations near the $2988 \mathrm{~W}$. Thus, in the sunlight intensity to $800 \mathrm{~W} / \mathrm{m}^{2}$, the simulation system using fuzzy control than non-using control the output power is higher $765 \mathrm{~W}$; in sunshine intensity $1000 \mathrm{~W} / \mathrm{m}^{2}$, the output power increased to $2122 \mathrm{~W}$.

\section{Summary}


In this paper, we directly put the duty cycle step as a control variable via photovoltaic power generation system modeling analysis. We use fuzzy control to adaptive adjustment the duty cycle according to the magnitude of photovoltaic power change. Simulation results show that: with fuzzy control, photovoltaic power generation system can efficiently track the maximum power point of photovoltaic arrays; At the same time, it also can quickly find the new maximum power point in the case of light intensity and other parameters mutated.

\section{References}

[1] Hua Chihchiang,Shen Chihming. The 29th IEEE Annual Conference on Power Electronics Specialists, 1998, 86-93

[2] HOHM D P, ROPP M E.IEEE 28th Photovoltaic Specialists Conference. 2000.1699-1702.

[3] Yu G J, Jung Y S,Choi J Y,et al.The 29th IEEE Conference on Photovoltaic Specialists,2002, 1531-1534.

[4] EFICHIOS KOUTROULIS, KOSTAS KALAITZKIS,VOULGARIS C. IEEE Transaction on Power Electronics,2001,16(1):46-54.

[5] Xiao Weidong, Dunford W G. 35th IEEE Annual Conference on Power Electronics Specialists, 2004,1957-1963. 